\title{
On the applications of peroxodiphosphate produced by BDD-electrolyses
}

Ana Sánchez, Javier Llanos*, Cristina Sáez, Pablo Cañizares, Manuel A. Rodrigo

Department of Chemical Engineering. Faculty of Chemical Sciences and Technologies.

University of Castilla-la Mancha. Avda. Camilo José Cela, 12. 13071 Ciudad Real.

Spain.

* To whom correspondence should be addressed. Tel. +34 902204100 Ext. 3508

Fax: +34926295256

E-mail: javier.1lanos@uclm.es 


\begin{abstract}
Peroxodiphosphate can be produced efficiently by electrolyses of phosphate solutions with boron-doped diamond electrodes. This oxidant is proposed in literature as a promising alternative to persulphates and to other oxidants typically used in environmental remediation processes and it is also known to have a significant role in the understanding of the electrolyses of wastes polluted with organics when phosphates are contained in significant concentrations in the waste. This manuscript clarifies the reactivity of solutions containing electrochemically produced peroxophosphate solutions with various aromatic (phenol and naphthol) and aliphatic (maleic acid and 2propanol) organic pollutants and also with cyanide, and compares results obtained in these chemical oxidation test with those obtained using similar oxidants such as hydrogen peroxide, peroxosulphate and hypochlorite. Results show that peroxodiphosphate can oxidize organic pollutants but it is much less powerful than hydrogen peroxide. Opposite, the oxidation of cyanide with this oxidant seems to offer significant advantages if compared with that of hypochlorite and shows a very promising process to treat efficiently wastes polluted with cyanide. In every case, it was demonstrated that oxidation efficiency of peroxophosphate produced electrochemically is much more significant than that shown by commercial peroxosulphate.
\end{abstract}

\title{
Keywords
}

peroxodiphosphate, cyanide, organic matter, oxidation, waste treatment 


\section{Introduction}

Peroxoacids and peroxosalts are a group of oxidants that are characterized by containing a peroxo group $(-\mathrm{O}-\mathrm{O}-)$. Some representative examples of this group are peroxocarbonates, peroxoacetates, peroxosulphates and peroxophosphates. Generally, most of these oxidants can be easily stored and transported due to its high stability at well known conditions, being this characteristic of a significant importance when compared to other oxidants. As an example, peroxodiphosphate shows a great stability at $\mathrm{pH} 12.5$ while it becomes highly reactive when $\mathrm{pH}$ is modified significantly from this value. For this reason, these compounds have been proposed for several environmental and industrial applications.

Peroxophosphates present a wide variety of applications such as oxidant in organic synthesis [1, 2] and in water treatment [3], ingredient of cosmetics [4, 5], agricultural products [6], and as bleaching agents in the detergents industry [7, 8]. Moreover, peroxodiphosphates may be used in similar applications as peroxosulphates, due to the similar properties that present both compounds. Among these applications, it is worth mentioning finishing of printed circuits, cleaning of metal surfaces prior to deposition processes or regeneration of activated carbon [9]. In this case, peroxodiphosphate exhibit an important advantage when compared with peroxodisulphate, as the reduction product (phosphate) can be much more easily and economically removed from the treated water by a single precipitation.

Among peroxophosphates, peroxodiphosphate can be obtained by electrochemical synthesis (Eq. 1) with an efficiency that is strongly dependent on the anode material used $[10,11]$.

$$
2 \mathrm{PO}_{4}{ }^{3-} \rightarrow \mathrm{P}_{2} \mathrm{O}_{8}{ }^{4-}+2 \mathrm{e}^{-}
$$

As oxygen evolution is a competing reaction (Eq. 2), the best anode materials to carry out the synthesis of peroxodiphosphate are expected to be those with a high overpotential for this side reaction (Eq. 2).

$$
2 \mathrm{H}_{2} \mathrm{O} \rightarrow \mathrm{O}_{2}+4 \mathrm{H}^{+}+4 \mathrm{e}^{-}
$$


Nevertheless, as it happens with the well-known peroxosulphate electrochemical synthesis $[11,12]$, the majority of these anode materials (mainly lead and tin oxides coatings) were known to suffer corrosion problems, in particular when they are used in harsh conditions, such as the required in the manufacturing of peroxocompounds, exhibiting low average lifetime and occasionally resulting in products unpurified with highly toxic compounds [13]. For this reason, for years, platinum had been the most used anode material for the peroxodiphosphate and peroxodisulphate synthesis [14]. However, addition of additives to increase the low electrochemical yield is needed and this addition results in an unpurified peroxocompound [15].

All these drawbacks were solved with the development of novel anode materials based on conductive diamond coatings, in particular with the boron doped diamond. Successful electrosynthesis of peroxocompounds such as peroxosulphates [16], peroxodiphosphate [17-19] and peroxomonophosphoric acid [20] have been recently reported, showing high current efficiencies and other significant advantages as compared to previous processes, in particular the purity of the products because no additives were required. As it is shown in the graphical abstract, the synthesis of peroxodiphosphate can take place directly or mediated by hydroxyl radicals. Likewise, many other oxidants have been synthesized with this technology [21, 22] showing great advantages as well.

Taking into account this background, the present work aims at evaluating the performance of peroxodiphosphate produced electrochemically (by electrolyses with BDD anodes), more specifically in the field of wastewater treatment. This product does not contain any additive and it is reduced to phosphate. This means that when applied, only peroxodiphosphate and phosphate are expected. To the authors' knowledge, in spite of the various works in which the production is aimed, no work reported the features of the product formed in its use as oxidant for environmental applications. Results obtained are of importance not only because a direct application of peroxodiphosphate is looked for, but also because they can help to clarify the role of these oxidants in oxidation mechanisms occurring during anodic oxidation of organics when phosphate ions are contained in the waste and chemical oxidation by peroxophosphates of organics occurs at a significant rate. 


\section{Experimental}

The procedure of $\mathrm{P}_{2} \mathrm{O}_{8}{ }^{4-}$ synthesis is described elsewhere [18]. This process was carried out at bench-scale in a double-compartment (separated by a cationic exchange membrane, STEREOM L-180) flow-pass electrochemical cell, under galvanostatic (current density of $1250 \mathrm{~A} \mathrm{~m}^{-2}$ ) and temperature control conditions $\left(25^{\circ} \mathrm{C}\right)$. Both the anolyte and the catholyte, consisted of solutions of potassium phosphate (1 M) and the required amount of $\mathrm{KOH}$ to give a final $\mathrm{pH}$ of 12.5 . A very important point is that during the synthesis, $\mathrm{pH}$ was maintained constant at 12.5 in the anolyte by the continuous addition of potassium hydroxide, in order to maximize efficiency (at this $\mathrm{pH}$ peroxodiphosphate stability is maximum).

To carry out the oxidation tests described in Section 3.2, a set of $250 \mathrm{~cm}^{3}$ glass reactors was used. They were mixed magnetically in a multi-stirrer device coupled with a thermostatic bath and the temperature of the reaction was controlled and set to $20{ }^{\circ} \mathrm{C}$. For any test, a volume of $200 \mathrm{~cm}^{3}$ of the target solution (COD concentration of $500 \mathrm{mg}$ $\mathrm{dm}^{-3}$ ) was added to the reactor. Next, the required dosing of oxidant was added to the reactor. The oxidant dosing will be expressed with respect to the stoichiometric ratio required to get a complete oxidation of the target pollutant to $\mathrm{CO}_{2}$ and $\mathrm{H}_{2} \mathrm{O}$. The length of the tests was 3-4 hours for the kinetic tests and 24 hours for the efficiency tests (steady state response). Finally, the performance of peroxodiphosphate will be compared to other oxidants typically used in wastewater treatment. To do this, the same procedure has been used.

\section{Results and discussion}

\subsection{Feasibility of the process: review of the electrochemical production of peroxodiphosphate}

In previous works $[17,18]$, the electrochemical production of peroxodiphosphate by electrolyses with BDD anodes was studied, and the influence of the main operation parameters on its efficiency was assessed. It was found that [17]: 
- a minimum current density (j) was required in order to promote formation of hydroxyl radicals. However, it should not be very large in order to avoid an unnecessary increase of cell voltage by ohmic drops, and thus, avoidable increases in energy costs,

- in order to avoid loses of efficiency due to chemical decomposition, a strict regulation of temperature $(\mathrm{T})$ and specially of $\mathrm{pH}$ should be kept during electrolyses, in order to maintain them as close as possible to optimum conditions.

The particular features of the diamond coatings were also found to be very significant in order to attain high efficiencies in the electrosynthesis [18]. Thus it was assessed that the thinner the diamond-layer, the better the efficiencies obtained in the production of peroxophosphates and that high boron contents of the coating also have a positive influence on the efficiency of the process.

Taking into account these points, to attain the amount product required to be used in the next sections of this work, several electrolyses were carried out. In those electrolyses, made in the discontinuous mode of operation, the optimum operation conditions found in previous works $[17,20]$ were kept during all the operation time $\left(\mathrm{T}=25^{\circ} \mathrm{C} ; \mathrm{pH}=12.5 ; \mathrm{j}\right.$ $=1250 \mathrm{~A} \mathrm{~m}^{-2}$ ) and a diamond with a boron contents of $8000 \mathrm{ppm}, \mathrm{a} \mathrm{sp}^{3} / \mathrm{sp}^{2}$ carbon ratio of 80 , and a thickness of the diamond surface of $1.05 \mu \mathrm{m}$ was used.

Hence, by electrolysis with BDD anodes solutions containing peroxophosphates are obtained. Role of these oxidants should be taken into account in oxidation mechanisms occurring during anodic oxidation of organics in case chemical oxidation by peroxophosphates of organics occurs (this point was not studied before and it is one of the goals of this manuscript). For this reason, and although, a selective precipitation with methanol can allow us to purify the product and to recover it as a solid, it was decided to assess directly these solutions because, in this way, we can attain a double aim: (i)known more about anodic oxidation processes and (ii) about oxidation of organics by electrochemically produced. Next, the applications of this electrochemically-formed peroxodiphosphate in the field of wastewater treatment will be evaluated. 


\subsection{Applications of peroxodiphosphate in the treatment of wastewater.}

To assess characteristics as oxidant of electrochemically-produced peroxodiphosphate solutions, dosing of this reagent to synthetic wastewater containing five selected model pollutants were studied. Two species were used as model of aromatic pollutants (phenol and naphthol), two as model of aliphatic pollutants (2-propanol and maleic acid) and one as model of inorganic pollutant (cyanide). These studies aimed to determine the rate and extension of the oxidation processes and to compare the efficiency of peroxodiphosphate in the removal of these pollutants with that obtained for other oxidants.

\subsubsection{Oxidation of organic model pollutants with peroxodiphosphate}

Figure 1 shows the time course of the Chemical Oxygen Demand (COD) just after the addition of the oxidant solution, during the chemical oxidation of the organic species assessed. In every case, the dosage of oxidant was 3 times over the stoichimetric ratio required for the complete depletion of the pollutant (i.e. an excess of oxidant over the stoichiometric requirement of a 300\%) in order to attain conditions in which dose of oxidant are not limiting the oxidation process.

As it can be observed, COD decreases rapidly after the addition of the peroxodiphosphate solution down to a constant value, very far from the total depletion of the pollutant. This behavior indicates that target pollutants are oxidized in every case to refractory chemicals (i.e. species not viable, or at least difficult, to be oxidized with this technology). Total decrease of COD observed is larger for the oxidation of aromatic model pollutants and very small for the oxidation of aliphatic model species. However, initial rates of the oxidation process (initial decrease of the COD just after the addition of the peroxodiphosphate solution) seem to be very comparable. This is clearly observed in Figure 2, which shows the initial oxidation rate of the target organic pollutants as a function of the concentration of peroxodiphosphate, expressed as overdosing with respect to the stoichiometric requirement. As it can be observed, the oxidation rate follows a first order kinetics with respect to the concentration of peroxodiphosphate and clearly depends on the oxidant concentration and not on the 
nature of the pollutant which is oxidized. This means that opposite to what it has been suggested in many reviews about potential uses of peroxodiphosphate, this reagent does not behave as a selective oxidant at least from the kinetic point of view. This is not in disagreement with the observation of formation of refractory species because it only indicates that when a molecule can be oxidized, the rate does not seem to depend on the nature of the organic pollutant. At this point, it is important to clarify that this conclusion is restricted to the organic molecules tested in the present work and that the experimental procedure should be repeated to extrapolate this conclusion to other different organic pollutants. However, it seems clear that there are refractory species formed during the treatment.

Figure 3 shows the evolution of the total organic carbon (TOC) in long-term oxidation tests, carried out to check the maximum removal of pollution which could be attained by peroxodiphosphate solutions.

As it can be observed, the mineralization ratio does not depend on the nature of the pollutant but on the dosage of peroxophosphate, being necessary a high overdosing to reach significant mineralization. This means that the target organic pollutant is not transformed into carbon dioxide but into other refractory organics.

To check the progress of the oxidation, COD is expected to give much more significant information, because it does not focus only on the transformation of organic carbon into carbon dioxide but it accounts for all oxidation processes of the raw pollutant or reaction intermediates. Changes of this parameter with the oxidant dose are shown in Figure 4. In this case, the efficiency of COD removal by the dosing of peroxodiphosphate clearly depends on the target organic pollutant.

As it can be observed, the shape of the different plots is reminiscent of a very wellknown oxidation process: the breakpoint chlorination reaction. For an oxidant overdose below 3 (with respect to the stoichiometric ratio) the higher the oxidant concentration the higher the removal of COD attained at the steady-state. On the contrary, for ratios between 3 and 5, the percentage of COD removal decreases or remains constant when increasing the oxidant dosing. For overdoses higher than 5, the process efficiency increases again with the oxidant dosing. This behavior can only be explained by the coexistence of different oxidation mechanisms. Once the oxidant is dosed into the 
solution, it can react with organic matter or it can be destroyed by different decomposition mechanisms. This last possibility can help to explain the behavior for oxidant overdose ratios between 3 and 5, if competing oxidation of difficult to oxidize organics and decomposition of peroxodiphosphate are accounted. For higher or lower ratios, the reaction of organic matter oxidation is dominant and the removal of COD increases for increasing peroxodiphosphate dosing.

Once clarified the oxidation capacity of organics with peroxodiphosphate, it is interesting to compare it with that of other competing oxidants, in order to have a clear idea of its role in mediated electro-oxidation processes and also of its potential use as substitutive of these oxidants. To do this, chemical oxidation tests of the same model pollutants with hydrogen peroxide (a well known soft oxidant based also on the action of the peroxo group) and with commercial peroxodisulphate (an oxidant with similar properties according to literature) were carried out. Figures 5 and 6 show for aromatic and aliphatic pollutants, respectively, the initial oxidation rate of the oxidation process with the three oxidants as a function of the overdose used respect to the stoichiometric ratio.

It can be observed that there are significant differences among the three oxidants assessed, in spite the peroxo group is always the responsible of the oxidation. Hydrogen peroxide is the oxidant that most rapidly reacts with aromatics and it is also observed that this oxidant overcomes peroxophosphates and peroxosulphates in the case of wastewaters polluted with aliphatic compounds, although the differences observed between hydrogen peroxide and the rest of the selected oxidants are less pronounced in this latter case. This is important for the understanding of the processes occurring during anodic oxidation of wastewater, because in those conditions several oxidants are produced and differences of reactivity are frequently explained in terms of the potential role of oxidants which cannot be measured because they are expected to react once they are produced in the system. It is important to take into account that comparison was made with molecular hydrogen peroxide and that achievement of this oxidant can be even promoted by adding cupper or iron metal ions, by means of the well-known Fenton process, or by the synergistic combination with other oxidant (hydrogen peroxide and ozone combination is known to result in hydroxyl radical formation).

Regarding commercial peroxosulphate, it can be observed that it is the worse oxidant in terms of oxidation rate, being the oxidation rate attained for every dose of oxidant much 
smaller than that attained by the electrochemically formed peroxophosphate solution. Hence, from the viewpoint of organic oxidation in wastewater treatment, it can be stated that peroxophosphate is a potential oxidant, although it could not be recommended its use because efficiencies attained in the oxidation are far away from those expected for an oxidant with environmental interest.

\subsubsection{Oxidation of cyanide with peroxodiphosphate}

The last model pollutant assessed in this work is cyanide which, nowadays, is typically removed from wastewater by chemical oxidation with hypochlorite. Figure 7 shows the changes in the cyanide concentration with time after the addition of different doses of peroxodiphosphate solution to a potassium cyanide synthetic wastewater (in alkaline media).

As it can be observed, and opposite to the behavior observed for organic pollutants, cyanide solutions can be efficiently treated by the addition of peroxodiphosphate, getting much higher removal efficiencies than those observed during the oxidation of organics and reported in the former section. Thus, in this case for an overdose as small as 1.2 an almost complete cyanide removal is obtained. No cyanates were detected in the reaction media during the oxidation process, meaning that oxidation can be understood as a direct transformation of cyanide into carbon dioxide and nitrogen, as shown in Eq. 3.

$$
5 \mathrm{P}_{2} \mathrm{O}_{8}{ }^{4-}+2 \mathrm{CN}^{-}+8 \mathrm{OH}^{-} \rightarrow 2 \mathrm{CO}_{2}+\mathrm{N}_{2}+4 \mathrm{H}_{2} \mathrm{O}+10 \mathrm{PO}_{4}{ }^{3-}
$$

It is interesting to compare characteristics of peroxodiphosphate as oxidant of cyanide with that of hypochlorite (the oxidant typically used in depletion of cyanide from wastewater) and with commercial peroxosulphate (in order to assess if there are also differences between these two oxidants in the oxidation of cyanide). In this case, oxidation by hydrogen peroxide was not assessed because this oxidant is more efficient when working at acidic $\mathrm{pH}$ than at basic $\mathrm{pH}\left(\mathrm{E}^{0}=1,763 \mathrm{~V}\right.$ a $\mathrm{pH}=0, \mathrm{E}^{0}=0,878 \mathrm{~V}$ a $\left.\mathrm{pH} 14\right)$ and, in these conditions, formation of cyanhydric acid, a highly toxic compound, is 
attained. Figure 8 shows the results obtained in these tests comparing oxidations in terms of rate (part a) and effectiveness of depletion (part b).

As it can be observed, the lowest initial rate for the oxidation of cyanide is attained for peroxodisulphate, meanwhile the highest is obtained when using hypochlorite, being peroxodiphosphate behavior closer to hypochlorite than to peroxosulphate, in spite of greatest chemical similarity with this latter oxidant. Moreover, it can be observed that the initial oxidation rate does not seem to depend on the concentration of peroxodiphosphate, thus presenting a zero order kinetics under the selected experimental conditions assessed.

On the other hand, as it can be observed in Figure 8.b, the highest effectiveness of the process in terms of cyanide depletion (the percentage of cyanide removed at the steady state) is obtained when dosing the peroxodiphosphate solution. Likewise, it can be observed clear increases of cyanide removal for increasing peroxodiphosphate concentrations. Thus, although the initial oxidation rate of cyanide with peroxodiphosphate is not the highest, the total removal efficiency is higher than that reached with other oxidant agents, allowing an almost complete removal of cyanide.

The better performance of peroxodiphosphate in terms of the higher removal of cyanide may be related to its high reduction potential $\left(\mathrm{E}^{0}\left(\mathrm{P}_{2} \mathrm{O}_{8}{ }^{4-} / 2 \mathrm{PO}_{4}{ }^{3-}\right)=2.07 \mathrm{~V}\right.$, [23]). Nevertheless, this oxidation potential is almost the same as the standard reduction potential of peroxodisulphate [24], although this oxidant exhibits a poorer performance in the removal of cyanide. In order to explain this result, the observations of Kulmala et al., about the reduction potential of first one-electron step of both oxidants, can be considered. According to their observations, peroxodiphosphate ions are stronger oneelectron oxidants than peroxodisulphate. This behavior is related to the fact that phosphate radicals are much stronger oxidants than sulphate radicals and, thus, the reduction potential of the first one-electron step of peroxodiphosphate should consequently be much higher than that of peroxodisulphate. Regarding hypochlorite, the most widely used method for cyanide removal is the chemical oxidation by alkaline chlorine. In this process, chlorine can be added either as free chlorine or as hypochlorite, although the latter is always the oxidant agent as this process works at basic $\mathrm{pH}$. This process of cyanide oxidation is well-known, and it is summarized in Eqs. 4 to 6.

$$
\mathrm{NaCN}+\mathrm{Cl}_{2} \rightarrow \mathrm{CNCl}+\mathrm{NaCl}
$$




$$
\begin{aligned}
& \mathrm{CNCl}+2 \mathrm{NaOH} \rightarrow \mathrm{NaCNO}+\mathrm{H}_{2} \mathrm{O}+\mathrm{NaCl} \\
& 2 \mathrm{NaCNO}+4 \mathrm{NaOH}+3 \mathrm{Cl}_{2} \rightarrow 2 \mathrm{CO}_{2}+6 \mathrm{NaCl}+\mathrm{N}_{2}+2 \mathrm{H}_{2} \mathrm{O}
\end{aligned}
$$

This process is actually carried out by two consecutive stages. The first stage, which involves reactions 4 and 5, is carried out at high $\mathrm{pH}$ values (ideally at values close to 11). At this working $\mathrm{pH}$ the rate of the process is increased and also the production of gaseous cyanogen chloride is avoided. In the second stage (reaction 6), the $\mathrm{pH}$ is decreased in order to enhance the reaction rate, which increases by $75 \%$ when decreasing $\mathrm{pH}$ from 10 to 8.5 . The most important problem of this process is its slowness, the high over-dosing required (up to $200 \%$ over the stoichiometric value), the chlorination of the reaction media, its salinization due to the $\mathrm{pH}$ adjustments and the potential formation of organochlorines if the target effluent contains organic matter ( $\mathrm{v}$. g. from lubricants). Moreover, it is necessary a thorough control of the $\mathrm{pH}$ in order to avoid the formation of cyanogen chloride. On the contrary, peroxodiphosphate avoids both problems and can be easily removed after the treatment by precipitation (chemical or electrochemical coagulation). Thus, cyanide removal from polluted wastewaters by chemical oxidation can be considered as a potential application of electrochemically produced peroxodiphosphate solutions.

\section{Conclusions}

The most relevant conclusions that can be drawn from this work are:

- Electrolyses with BDD anodes of phosphate solutions produce an ozidizing solution rich in peroxodiphosphates, which can oxidize organic pollutants and cyanide. This fact demonstrates the important role of mediated oxidation processed catalyzed by phosphate ions in electrolysis of wastewater with diamond electrodes.

- Peroxodiphosphate behaves as a non-selective soft oxidant in the oxidation of organics. The rate of oxidation of organic pollutants by peroxodiphosphate depends on the over-dosing of oxidant and not on the nature of the pollutant. For 
the removal of organic pollutants, hydrogen peroxide is much more efficient than peroxodiphosphate and, at the same time, peroxodiphosphate shows better efficiency than peroxosulphate, in spite of being the oxidation mechanism explained by the peroxo group.

- Cyanide oxidation by peroxodiphosphate is an efficient process, being the removal of cyanide almost complete for dosing slightly over the stoichiometric. When compared with chlorine and peroxodisulphate, peroxodiphosphate is the most efficient one. The removal of cyanide by the dosing of peroxodiphosphate avoids the most important problems related to the conventional treatment with hypochlorite: high over-dosing and salinization due to $\mathrm{pH}$ adjustments.

\section{Acknowledgements}

This work has been supported by the Spanish Government through the project CTM2010-18833/TECNO

\section{References}

[1] J. A. Rosso, F.J. Rodríguez, M.C. González, D.O. Martire, Reaction of phosphate radicals with substituted benzenes. J. Photochem. Photobiol. A. Chem. 116 (1998) 2125.

[2] J. A. Rosso, P. Caregnato, V.C. Mora, M.C. González, D.O. Martire, Reactions of phosphate radicals with monosusbtituted benzenes. A mechanistic investigation. Helvetica Chim. Acta. 86 (2003) 2509-2524.

[3] A.S. Groisman, A.D. Belyaeva, O.B. Khachaturayn, I.Y. Sugurova, (1991) US Patent 1699953 A1.

[4] B. Puetzer, A.V. Finn, L. Mackles, Tintex Corp. (1967) US Patent 3337466.

[5] B. Cohen, P.R. Mucenieks, FMC Corp. (1971) US Patent 3555147.

[6] Human Agricultural Collegev, T'uJang (Nanking), 1 (1978).

[7] A. Gaffar, D.B. Calvin (1983) DE Patent 3246946 A1.

[8] A. Gaffar, C.J. Edwards (1983) DE Patent 3627759 A1. 
[9] Kirk-Other, Encyclopedia of Chemical Tecnology, Vol. 18, Wiley- Interscinece Publications, New York (1996).

[10] C.J. Battaglia, J.O. Edwards, The Dissociation Constants and the Kinetics of Hydrolysis of Peroxymonophosphoric Acid. Inorg. Chem. 4(4) (1965) 552-558.

[11] Y.M. Kolotyrkin, A.A. Yakovleva, I.L. Kuvinova, Electrocatalytic activity of platinum, rhodium, iridium and their alloys in oxidising synthesis at high positive potentials. J. Electroanal. Chem. Interfacial Electrochem. 180(1-2) (1984) 241-256.

[12] D. Gandini, E. Mahe, P.A. Michaud, W. Haenni, A. Perret, Ch. Comninellis, Oxidation of carboxylic acids at boron-doped diamond electrodes for wastewater treatment. J. Appl. Electrochem. 30 (2000) 1345-1350.

[13] B. Correa-Lozano, Ch Comninellis, A. De Battisti, Service life of $\mathrm{Ti} / \mathrm{SnO}_{2}-\mathrm{Sb}_{2} \mathrm{O}_{5}$ Anodes. J. Appl. Electrochem. 27 (8) (1997) 970-974.

[14] O. G. Tyurikava, N. B. Miller, 1984 US Patent 1089174 A.

[15] C. J. Battaglia, J. O. Edwards, The dissociation constants and the kinetics of hydrolysis of peroxymonophosphoric Acid. Inorganic Chemistry 4 (4) (1965) 552-558

[16] K. Serrano, P.A. Michaud, Ch. Comninellis, A. Savall, Electrochemical preparation of peroxodisulfuric acid using boron doped diamond thin film electrodes. Electrochim. Acta 48 (2002) 431-436.

[17] P. Cañizares, F. Larrondo, J. Lobato, M.A. Rodrigo, C. Sáez, Electrochemical synthesis of peroxodiphosphate using boron-doped diamond anodes. Journal of the Electrochemical Society 152 (11) (2005) D191-D196.

[18] P. Cañizares, C. Sáez, A. Sánchez-Carretero, M.A. Rodrigo, Influence of the characteristics of p-si BDD anodes on the efficiency of peroxodiphosphate electrosynthesis process. Electrochemistry Communications 10(4) (2008) 602-606

[19] L. Hliwa, L.M. Ghallabi, M. Azzi, N. Saib, S. Maximovitch, F. Dalard, Phosphate oxidation on boron doped diamond electrode. Physical and Chemical News 56 (2010) 107-116.

[20] E. Weiss, C. Sáez, K. Groenen-Serrano, P. Cañizares, A. Savall, M.A. Rodrigo, Electrochemical synthesis of peroxomonophosphate using boron-doped diamond anodes. Journal of Applied Electrochemistry 38 (1) (2008) 93-100 
[21] C. Sáez, M.A. Rodrigo, P. Cañizares, Electrosynthesis of ferrates with diamond anodes. AIChE Journal 54(6) (2008) 1600-1607.

[22] M.E.H. Bergmann, T. Iourtchouk, J. Rollin, The occurrence of bromate and perbromate on BDD anodes during electrolysis of aqueous systems containing bromide: First systematic experimental studies. Journal of Applied Electrochemistry 41(9) (2011) 1109-1123.

[23] W.P. Griffith, R.D Powell, A.C. Skapski, Alkali-metal and ammonium peroxodiphosphates preparation, vibrational and P-31 NMR- spectra, and the X-Ray Cristal-Structure of ammonium peroxodiphosphate dehydrate $\left(\mathrm{NH}_{4}\right)_{4}\left[\mathrm{P}_{2} \mathrm{O}_{8}\right] \cdot 2 \mathrm{H}_{2} \mathrm{O}$. Polyhedron 7 (14) (1988) 1305-1310.

[24] E. Brillas, C.A. Martínez-Huitle, Synthetic Diamond Films. Preparation, Electrochemistry and Applications. Chapter 12. A. Sánchez-Carretero, C. Sáez, P. Cañizares, M. A. Rodrigo. Production of Strong Oxidizing Substances with BDD Anodes. (2011) John Wiley and Sons, Inc, New Jersey. 


\section{Figure captions}

Figure 1. Changes with time of the COD during the oxidation with electrochemically produced peroxodiphosphate solutions of synthetic wastewater $\left(\mathrm{COD}_{0}=500 \mathrm{mg} \mathrm{dm}^{-3}\right.$;

T: $20^{\circ} \mathrm{C}$ ) polluted with: (०) phenol; ( $\left.\mathbf{a}\right)$ maleic acid; ( $\boldsymbol{\Delta}$ ) naphthol; (x) 2-Propanol. Ratio COD-oxidant 1:3.

Figure 2. Influence of the ratio COD-oxidant on the oxidation rates at the initial moment measured for the oxidation with peorxodiphosphate of synthetic wastewater $\left(\mathrm{COD}_{0}=500 \mathrm{mg} \mathrm{dm}^{-3} ; \mathrm{T}: 20^{\circ} \mathrm{C}\right)$ polluted with: (०) phenol; (घ) maleic acid; ( $\left.\mathbf{\Delta}\right)$ naphthol; (x) 2-Propanol.

Figure 3. Influence of the stoichiometric ratio on the final value of Total Organic Carbon (TOC) after the chemical oxidation of: (०) phenol; ( $\mathbf{a})$ maleic acid; ( $\mathbf{\Delta})$ naphtol; (x) 2-Propanol, with peroxodiphosphate. $\left(\mathrm{COD}_{0}=500 \mathrm{mg} \mathrm{dm}^{-3}\right.$; T: $\left.20^{\circ} \mathrm{C}\right)$.

Figure 4. Influence of the stoichiometric ratio on the percentage of COD removal after the chemical oxidation of: ( $($ ) phenol; ( $\mathbf{a})$ maleic acid; ( $\boldsymbol{\Delta}$ ) naphtol; (x) 2-Propanol, with peroxodiphosphate. $\left(\mathrm{COD}_{0}=500 \mathrm{mg} \mathrm{dm}^{-3}\right.$; $\left.\mathrm{T}: 20^{\circ} \mathrm{C}\right)$.

Figure 5. Initial chemical oxidation rate of aromatics by different oxidants. Phenol: $(\circ)$ $\mathrm{H}_{2} \mathrm{O}_{2} ;(\square) \mathrm{P}_{2} \mathrm{O}_{8}{ }^{4-} ;(\triangle) \mathrm{S}_{2} \mathrm{O}_{8}{ }^{2-}$. Naftol: $(\bullet) \mathrm{H}_{2} \mathrm{O}_{2} ;(\bullet) \mathrm{P}_{2} \mathrm{O}_{8}{ }^{4-} ;(\Delta) \mathrm{S}_{2} \mathrm{O}_{8}{ }^{2-}$. ( $\left(\mathrm{COD}_{0}=500\right.$ $\left.\mathrm{mg} \mathrm{dm}{ }^{-3}\right)$.

Figure 6. Initial chemical oxidation rate of aromatics by different oxidants. 2-propanol

(०) $\mathrm{H}_{2} \mathrm{O}_{2} ;(\square) \mathrm{P}_{2} \mathrm{O}_{8}{ }^{4-}$ y $(\triangle) \mathrm{S}_{2} \mathrm{O}_{8}{ }^{2-}$. Maleic acid: $(\bullet) \mathrm{H}_{2} \mathrm{O}_{2} ;(\boldsymbol{\bullet}) \mathrm{P}_{2} \mathrm{O}_{8}{ }^{4-}$ y $(\Delta) \mathrm{S}_{2} \mathrm{O}_{8}{ }^{2-}$

$$
\left(\mathrm{COD}_{0}=500 \mathrm{mg} \mathrm{dm}^{-3}\right) \text {. }
$$

Figure 7. Changes with time of the concentration of cyanide during the Chemical oxidation of synthetic wastewater $\left(\left[\mathrm{CN}^{-}\right]_{0}=250 \mathrm{mg} \mathrm{dm}^{-3} ; \mathrm{T}: 20^{\circ} \mathrm{C}\right)$ with electrochemically produced peroxodiphosphate solutions. Ratios cyanide -oxidant: ( $\boldsymbol{\Delta})$

$$
1: 0.8 ; \text { (匹) } 1: 1.0 ; \text { ( }) 1: 1.2
$$

Figure 8.a. Oxidation rates at the initial moment during the oxidation of cyanide synthetic wastewater $\left(\left[\mathrm{CN}^{-}\right]_{0}=250 \mathrm{mg} \mathrm{dm}^{-3}\right)$ with different concentrations of $\mathrm{ClO}^{-}$,

$$
\mathrm{P}_{2} \mathrm{O}_{8}{ }^{4-} y^{-} \mathrm{S}_{2} \mathrm{O}_{8}{ }^{2-} \text {. }
$$

Figure 8.b. Influence of stoichiometric ratio on the percentage of $\mathrm{CN}^{-}$removal with different oxidants: $\mathrm{ClO}^{-}, \mathrm{P}_{2} \mathrm{O}_{8}{ }^{4-}$ y $\mathrm{S}_{2} \mathrm{O}_{8}{ }^{2-}$. $\left(\left[\mathrm{CN}^{-}\right]_{0}=250 \mathrm{mg} \mathrm{dm}^{-3}\right)$.

\section{Figures}




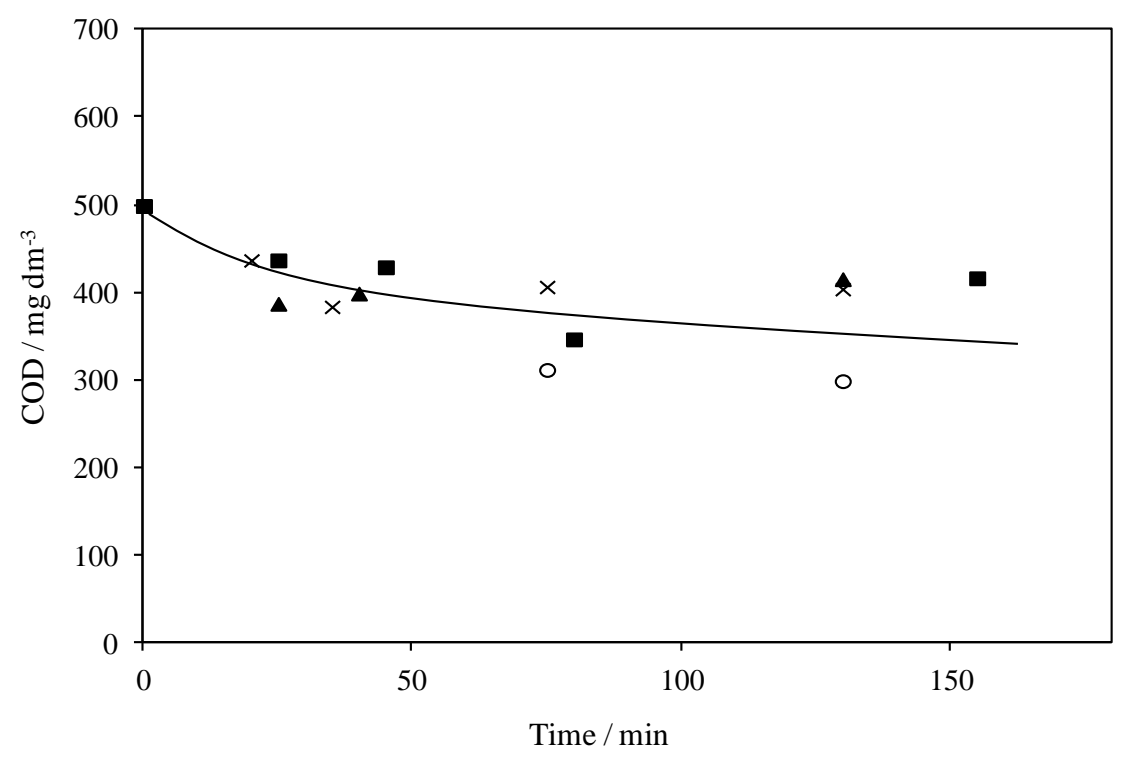

Figure 1



Figure 2 


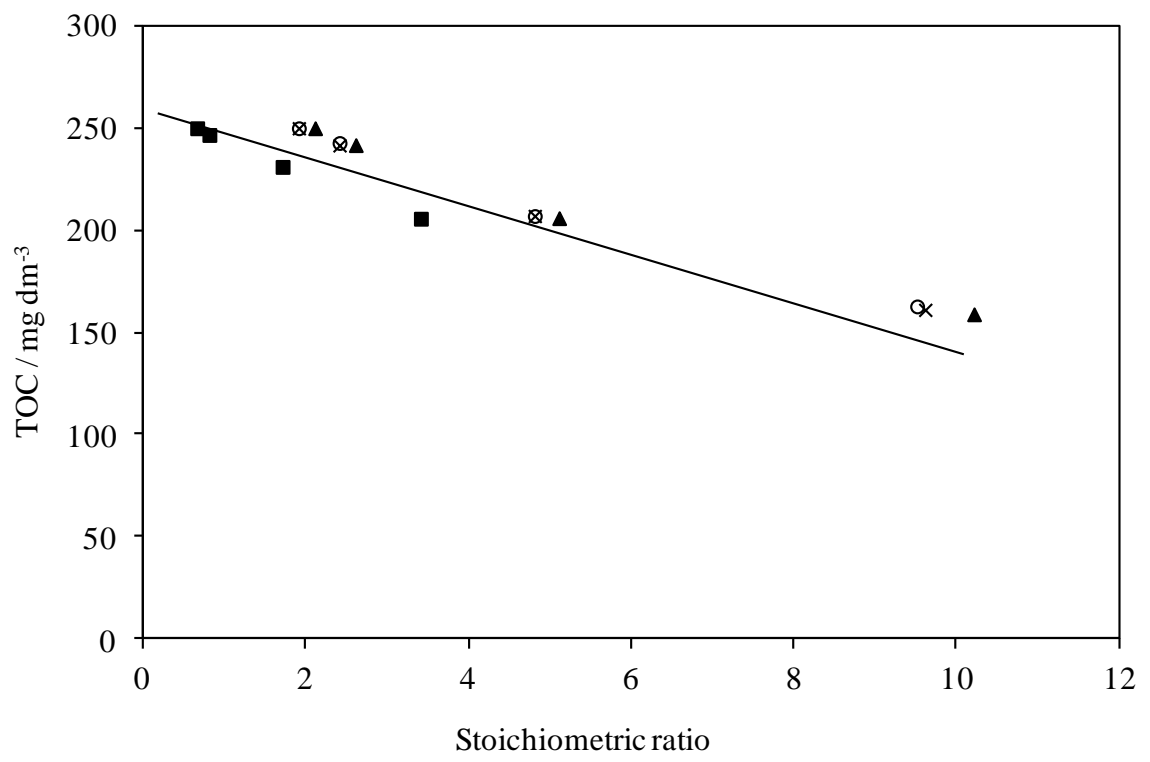

Figure 3



Figure 4 


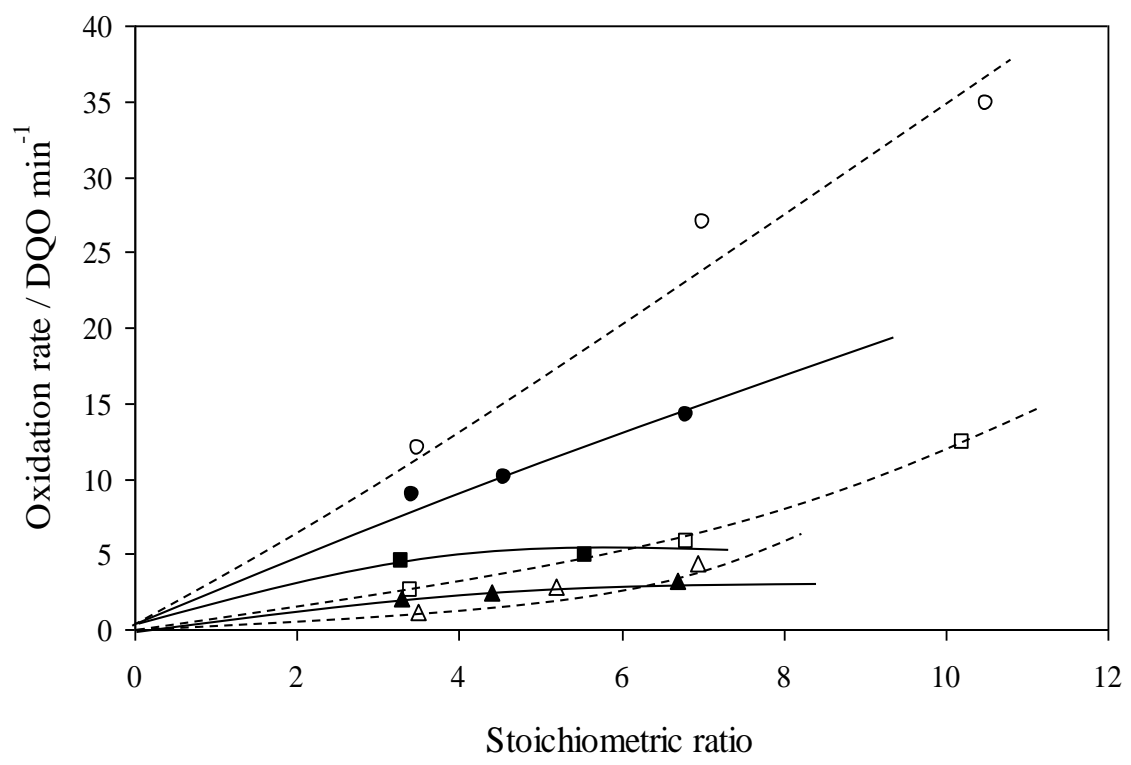

Figure 5

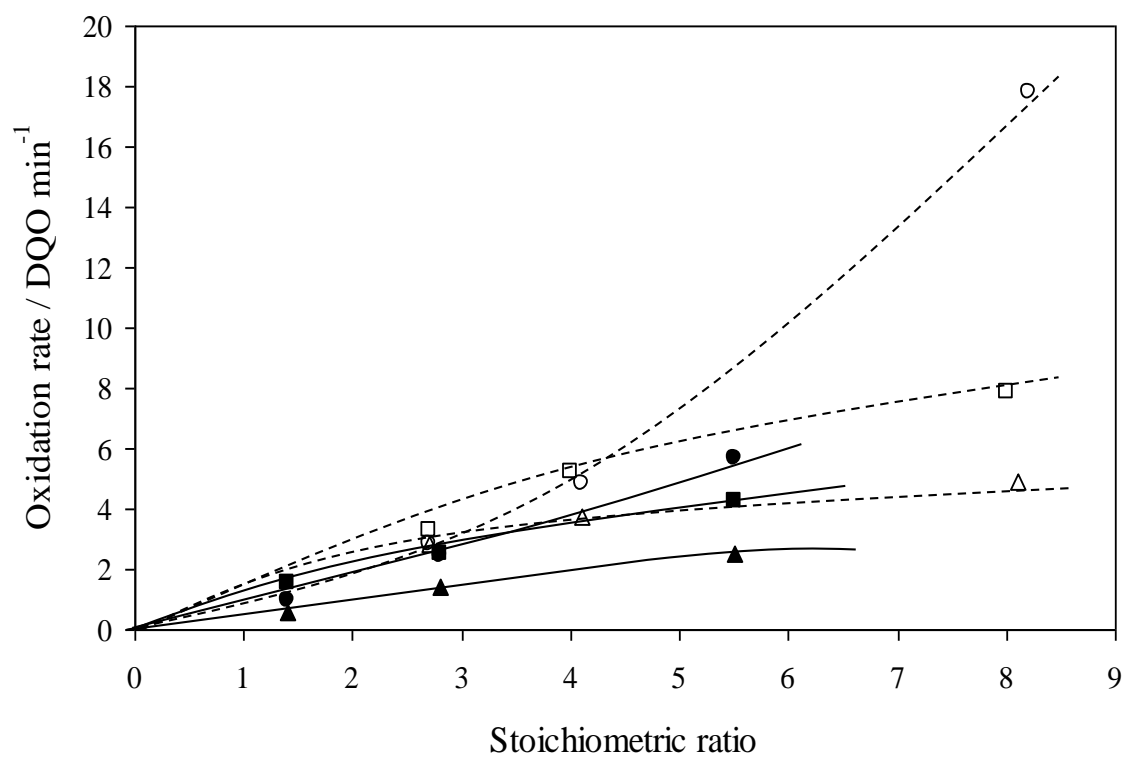

Figure 6 


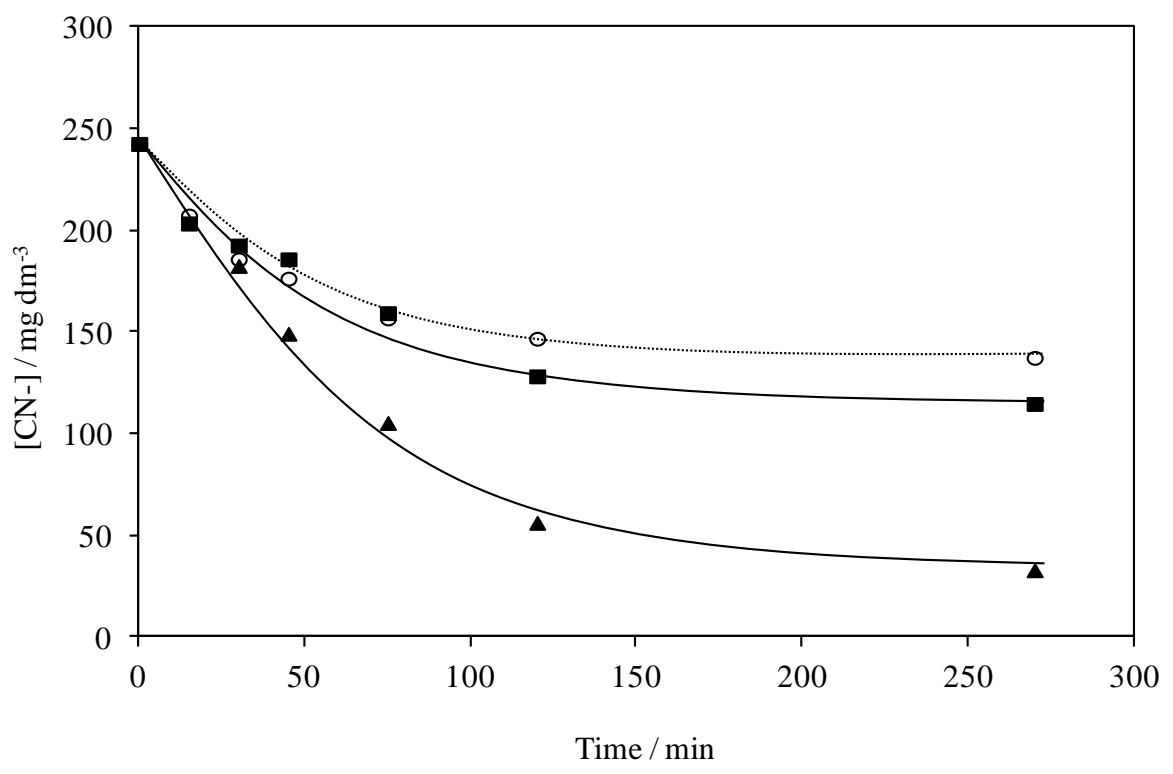

Figure 7

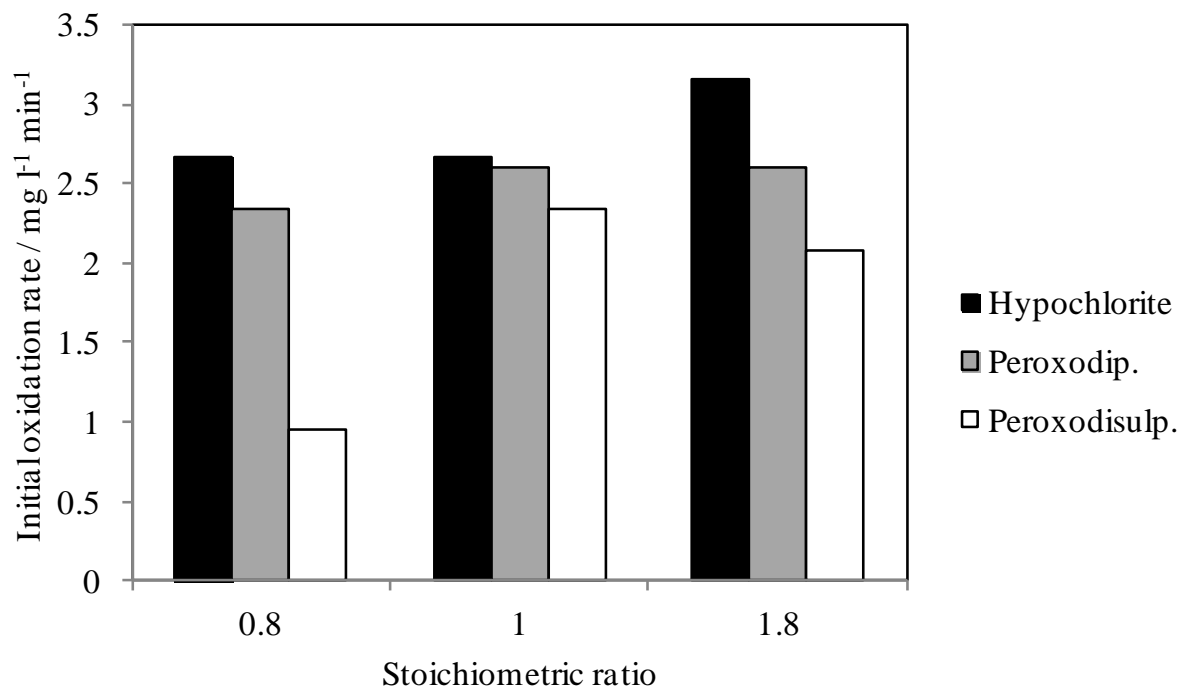

Figure 8.a. 




Figure 8.b. 